Ärztliche Erfahrung beschränkt sich nicht auf medizinisches Fachwissen.

\title{
Bauchschmerz-Rätsel nach einem Tag gelöst
}

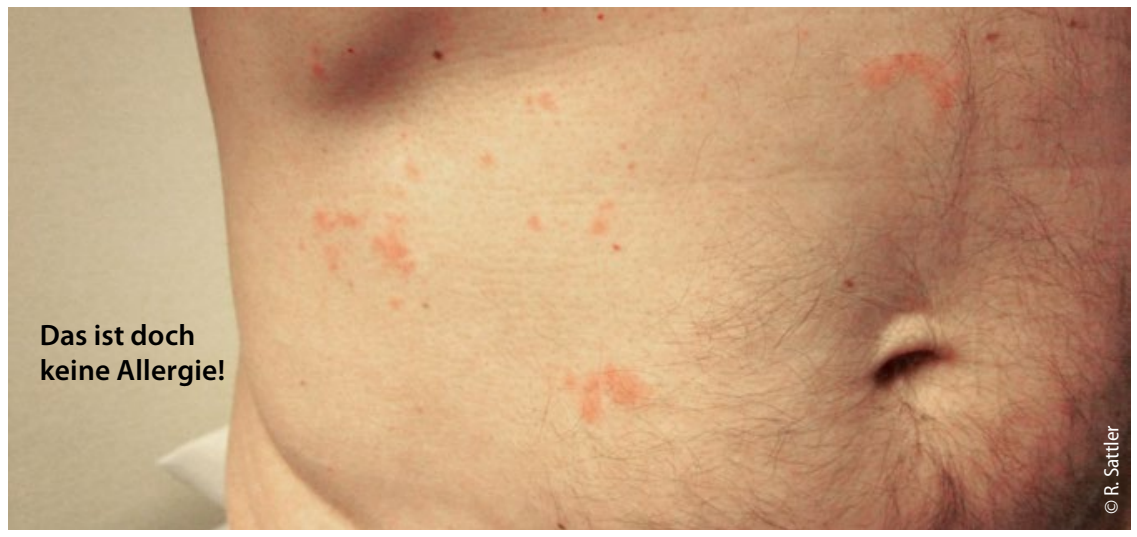

_ Mit unklaren rechtsseitigen Bauchschmerzen und einem nicht allzu guten Allgemeinzustand hatte sich mein Patient nachts in der Notaufnahme der örtlichen Klinik vorgestellt. Bei der Oberbauchsonografie wurde ein einzelnes Kolondivertikel gefunden, sonst aber nichts Auffälliges. Auch die Laborwerte waren unauffällig. Die Kollegen im Krankenhaus konnten sich keinen Reim auf die Schmerzen machen und entschieden sich erst einmal fürs Abwarten. Sie schickten den Patienten nach Hause und trugen ihm auf, sich am nächsten
Tag in unserer Praxis zur Kontrolluntersuchung vorzustellen.

Als er bei uns in die Sprechstunde kam, hatten sich die Schmerzen etwas verlagert. Der Patient bekundete, dass sie nicht mehr ganz so schlimm seien und jetzt auch in den Rücken ausstrah len würden. Zudem vermutete er, auf das Ultraschall-Gel allergisch reagiert zu haben, denn er habe nach der Untersuchung im Krankenhaus einen Ausschlag entwickelt.

Das wollte ich mir gleich einmal anschauen, und den Bauchbefund wollte ich im gleichen Zug auch noch mal kontrollieren. Letzteres wurde dann aber fast überflüssig, als ich den „allergischen Ausschlag" erblickte. Auf dem Bild erkennt man es sehr gut: eine ausgewachsene Gürtelrose!

Dr. Reinhard Sattler, Heiningen

\section{So funktioniert der Kreislauf}

_ Als Medizinstudentin einer mittelfränkischen Universitätsstadt durfte ich vor langer Zeit Zeuge eines Kundengesprächs in einer Apotheke werden, in dem der messerscharf formulierende Apotheker auf die fränkische Schnoddrigkeit eines älteren Herrn traf. „Ich bräucherd was gegen Kreislauf“, gab letzterer an. „Zu hoch oder zu tief?“, fragte der Apotheker knapp. Antwort: „Naaa, halt immer so im Kreis rum!“
Vermutlich erhielt der Mann ein frei verkäufliches Antivertiginosum, aber das bekam ich schon nicht mehr mit, da ich aufgrund eines Lachanfalls schnell die Apotheke verlassen musste. Doch diese wunderbare Interpretation hat mich geprägt. Wann immer ein Patient über Kreislaufbeschwerden klagt, taucht vor meinem inneren Auge eine rotierende Bewegung auf.

Dr. Ingrid Hermann-Siedler, Erlangen

\section{Für die Nierensteine gibt's den passenden Fachmann}

Ein Patient hatte Spuren von Blut im Harntest. Die Ultraschalluntersuchung ergab linksseitig zwei deutlich Schallschatten verursachende Nierensteine. Sichtlich betroffen vermutete der Patient: „Jetzt schicken Sie mich wohl weiter zum Geologen?!" Eigentlich logisch - Steinformationen werden ja gemeinhin von Geologen untersucht. In diesem Fall aber eher nicht. Sanft erklärte ich dem Patienten, dass für ihn der Urologe wohl die bessere Wahl wäre.

Dr. Herbert Zimmer, Freiburg 